\title{
RELATIONSHIP BETWEEN ACCESSIBILITY IMPROVEMENT AND RESIDENTIAL PROPERTY APPRECIATION: AN OBSERVATION FROM SHANGHAI METRO
}

\author{
Q. WU \& X. YE \\ Key Laboratory of Road and Traffic Engineering of Ministry of Education, Tongji University, China.
}

\begin{abstract}
The costly construction and operation of urban rail transit have become escalating problems for cities worldwide, especially in developing countries. Reliable measures of residential property appreciation for urban rail transit can provide suggestions for policy-making of value capture to fund transit improvements. Using GIS techniques and residential property price data, the relationships between accessibility improvement value and residential property appreciation are analysed in Shanghai. The impacts of urban rail transit on residential property values are classified into traffic effect and agglomeration effect, both of which are measured by the accessibility improvement model. The results indicate that the goodness-of-fit of the model is greater than $93 \%$. Traffic benefit is greater than agglomeration benefit in the suburb, which is completely different in the city centre. Furthermore, the residential property appreciation is about 5 times the accessibility improvement value per year. This study contributes to the evidence of capitalization impacts of public transit from a booming and transitional economy and provides suggestions for land use planning of areas surrounding stations.

Keywords: accessibility, agglomeration benefit, residential property appreciation, traffic benefit, transit-oriented development, urban rail transit.
\end{abstract}

\section{INTRODUCTION}

Traditional funding mechanisms, particularly for urban rail transit investments, have become increasingly inadequate, especially in China, a developing country. Because of the costly construction and operation, Chinese State Council had issued a notification to suspend all the underground rapid transit projects in the mid-1990s. Medda [1] presented that land value capture finance is often seen as an alternative method of revenue generation for urban rail transit systems. Although quantitative methods have been applied for nearly 20 years in China, the appreciation results according to different researchers are quite different, even for the same research object. Such differences may be due to the methods introduced from abroad which are not suitable for China. For example, the comparison method [2-4] can hardly be a fit in China because most cities have diverse land use and high-density land development. These land use patterns result in that it is extremely difficult to find a control area which has similar characteristics to its paired catchment area. The traffic cost method assumes that the city is mono-centric and the factors affecting residential property values are uniformly distributed while most Chinese cities are typically multi-centric or cluster-developed and have more than one Central Business District (CBD) in a city. The hedonic price model tries to estimate the implicit value of the determinant factors on the prices of heterogeneous goods [5, 6] by using the residential property transaction data and characteristics description, which are 
easily obtained in many developed countries but difficult to be obtained currently in China. So a new approach to measure the impacts of urban rail transit on residential property values should be made. This paper considers the essential impact factors and quantifies them from the point of view that the main function of urban rail transit is to improve accessibility. Using GIS techniques and residential property price data, the relationships between accessibility improvement value and residential property appreciation are analysed in Shanghai.

\section{ACCESSIBILITY IMPROVEMENT MODEL}

\subsection{Impact factor analysis}

The primary function of urban rail transit is to improve travel accessibility around station areas. At the same time, it can promote land development, population gathering and job growth. Although these agglomeration benefits are some kind of economic phenomenon, the major reason is the convenient transportation from other origins to the stations by urban rail transit, which is called attract accessibility. Therefore, the impacts of urban rail transit on residential property values can be divided into two parts. One is travel benefit, called travel accessibility improvement. The other is agglomeration benefit, called attract accessibility improvement. However, rail transit may also bring negative impacts to property value $[1,7,8]$. Since the negative impacts are factored into the final transaction price, they are ignored in this article. The accessibility improvement model will be established as follows.

\subsection{Modelling}

No matter what the purpose of a trip, it will take a certain amount of cost. If the construction of a new transport facility reduces the original travel costs, the reduced part can be regarded as benefits brought by the new transport facility. Therefore, the accessibility improvement provided by urban rail transit is defined as the decrease of travel costs after the operation of urban rail transit. Since the most public transit trips within a city rely on bus transit before the construction of urban rail transit in China, the travel costs before the operation of urban rail transit are supposed to be the travel cost by bus transit. Although the bus transit also has slight impact on residential property values, it is not discussed in this study. For a generalized travel starting from a rail station, the generalized destinations are identified as areas within walking distance from other stations in the urban rail transit network of the city [9]. So the accessibility improvement is the weighted average of generalized travel cost differences between urban rail travels and bus travels starting from a rail station to areas within walking distance from other stations.

\subsubsection{Travel accessibility improvement}

From the residence to the starting rail station, shuttle transportation modes are generally required, such as walking, cycling, bus, taxi or private car in China. Because of the high coverage density of bus stops, the default shuttle transportation mode of bus is walking. So the travel accessibility improvement of a generalized travel from the residence to a generalized destination is the sum of the shuttle transportation accessibility improvement and the travel accessibility improvement excluding the shuttle transportation. 


\section{COMPRAIL}

First, the shuttle transportation accessibility improvement expression is as follows:

$$
\Delta C_{i}(r)=C_{d}(r)-\sum_{k=1}^{K} \gamma_{k}(r) \cdot C_{r k}(r),
$$

where $r$ is the network distance from the residence to the starting rail station. $C_{d}(r)$ is the generalized shuttle transportation cost from the residence to the starting bus stop. $\gamma_{k}(r)$ is the sharing rate of the shuttle transportation mode $k(k=1,2,3 \ldots K$, and $K$ is the number of the shuttle transportation modes). $C_{r k}(r)$ is the generalized shuttle transportation cost from the residence to the starting rail station by mode $k$. The generalized shuttle transportation costs include fares, travel time and private transportation depreciation charges, all of which are converted to a unified monetary unit by the time value [9].

Second, the travel accessibility improvement excluding the shuttle transportation is calculated as follows:

$$
\Delta C_{i}=\frac{\sum_{\substack{j=0 \\ j \neq i}}^{J} \omega_{i j 1} \cdot\left(C_{i j d}-C_{i j r}\right)}{J}=\frac{\sum_{\substack{j=0 \\ j \neq i}}^{J} \frac{\sum_{m=1}^{M} \alpha_{m} E_{j m}}{M} \cdot \frac{C_{i 0 r}}{C_{i j r}} \cdot\left(C_{i j d}-C_{i j r}\right)}{J},
$$

where $\omega_{i j 1}$ is the travel importance weight from the rail station $i$ to $j(j=0,1,2, \ldots, J$, and $j \neq i, J$ is the number of urban rail transit stations within the city). $C_{i j d}$ is the generalized travel cost from the bus stop near the rail station $i$ to the bus stop near the rail station $j$ by bus. $C_{i j r}$ is the generalized travel cost from the rail station $i$ to $j$ by urban rail transit. $E_{j m}$ is the number of job $m$ in the impact range of the rail station $j(m=1,2,3, \ldots, M$, and $M$ is the number of job types). $\alpha_{m}$ is the number of attracting visitors per job $m$ (obtained by survey). $E_{0 m}$ is the number of job $m$ in the impact range of the centre station. $C_{i 0 r}$ is the generalized travel cost from the rail station $i$ to the centre station. The serial number of the centre station is 0 . The generalized travel cost includes fares, travel time, transfer time and transfer punishment, all of which are converted to a unified monetary unit by the time value [9].

Assuming that the urban per capita daily travel frequency is $n_{i y}$ in the impact range of the rail station $i$ in year $y$, the travel accessibility improvement per capita in year $y$ is as follows:

$$
A_{i y}(r)=\left(C_{d y}(r)-\sum_{k=1}^{K} \gamma_{k y}(r) \cdot C_{r k y}(r)+\frac{\sum_{\substack{j=0 \\ j \neq i}}^{J_{y}} \frac{\sum_{m=1}^{M} \alpha_{m y} \alpha_{0 m y}}{M} \cdot \frac{C_{i 0 r y}}{C_{i j r y}} \cdot\left(C_{i j d y}-C_{i j r y}\right)}{J_{y}}\right) \cdot n_{i y} \cdot t,
$$

where the indicators which have the subscript $y$ are the corresponding values in year $y ; t$ is the service time of urban rail transit.

\subsubsection{Attract accessibility improvement}

The agglomeration benefits around urban rail transit stations are also attributed to convenient transportation from other origins to the stations by urban rail transit. Therefore, the attract 
accessibility improvement is the weighted average of generalized travel cost differences between urban rail travels and bus travels from other origin stations to the destination station $i$. Assuming that the urban per capita daily travel frequency is $n_{y}$ in the city in year $y$, the attract accessibility improvement per capita in year $y$ is as follows:

$$
B_{i y}=\frac{\sum_{\substack{j=0 \\ j \neq i}}^{J_{y}} \omega_{i j 2} \cdot\left(C_{i j d y}-C_{i j r y}\right)}{J_{y}} \cdot n_{y} \cdot t=\frac{\sum_{\substack{j=0 \\ j \neq i}}^{J_{y}} \frac{E_{i y}}{E_{0 y}} \cdot \frac{N_{j y}}{N_{0 y}} \cdot \frac{C_{i 0 r y}}{C_{i j r y}} \cdot\left(C_{i j d y}-C_{i j r y}\right)}{J_{y}} \cdot n_{y} \cdot t,
$$

where $B_{i y}$ is the attract accessibility improvement per capita in year $y . \omega_{i j 2}$ is the travel importance weight from the rail station $j$ to $i(j=0,1,2, \ldots, J$, and $j \neq i) . E_{i y}$ is the number of jobs in the impact range of the station $i$ in year $y . N_{j y}, N_{0 y}$ are the resident population in the impact range of the rail station $j$ and the centre station. $J_{y}$ is the number of urban rail transit stations within the city in year $y$.

\subsubsection{Accessibility improvement model}

In summary, the accessibility improvement model is as follows:

$$
D_{i y}(r)=A_{i y}(r)+B_{i y} .
$$

Assuming that the residential area per capita in the impact range of the rail station $i$ is $s_{i y}$ in year $y$, the accessibility improvement by urban rail transit for per square metre of residential in the impact range of the rail station $i$ is as follows:

$$
\begin{aligned}
& \overline{D_{i y}(r)}=\frac{D_{i y}(r)}{S_{i y}} \\
& =\left(C_{d y}(r)-\sum_{k=1}^{K} \gamma_{k y}(r) \cdot C_{r k y}(r)+\frac{\sum_{\substack{j=0 \\
j \neq i}}^{J_{y}} \frac{\sum_{m=1}^{M} \alpha_{m y} \alpha_{j m y} E_{0 m y}}{M} \cdot \frac{C_{i 0 r y}}{C_{i j r y}} \cdot\left(C_{i j d y}-C_{i j r y}\right)}{J_{y}}\right) \cdot \frac{n_{i y}}{S_{i y}} \cdot t \\
& \quad \sum_{\substack{j=0 \\
j \neq i}}^{J_{y}} \frac{E_{i y}}{E_{0 y}} \cdot \frac{N_{j y}}{N_{0 y}} \cdot \frac{C_{i 0 r y}}{C_{i j r y}} \cdot\left(C_{i j d y}-C_{i j r y}\right) \\
& \quad \frac{J_{y}}{S_{y}} \cdot t
\end{aligned}
$$

\section{RESIDENTIAL PROPERTY APPRECIATION CALCULATION METHOD}

Although the benefits associated near a rail station and other benefits are not easy to distinguish, $\mathrm{Wu}$ and $\mathrm{Ye}$ [10] designed a method to separate the benefits of urban rail transit from other benefits. The specific process is shown as the following.

The characteristics of residential property are generally divided into physical characteristics, neighbourhood characteristics and location characteristics $[7,8,11,12]$, which are the 
main factors affecting residential property values. The impact scope of urban rail station on residential property value is about 500 to $2000 \mathrm{~m}$ radius around a station, depending on the location of the station in the city and the size of the urban area. Within the same impact scope, most neighbourhood characteristics and location characteristics are generally similar. If the physical characteristics are controlled to be the same, the difference between the prices of residential property in different places within the same impact scope should only be caused by the distance to the nearest rail station.

Within the impact scope of a rail station, residential districts which have the similar physical characteristics are chosen as the research sample. A scatterplot about the average price per square metre and the distance to the station is drawn. Then a quadratic curve is adopted to fit the scatterplot. The inflection point of the price curve is the border of the impact scope, where the residential property appreciation is considered to be zero. The residential property appreciation at a certain place within the impact scope is calculated as follows:

$$
\Delta P_{i l}=P_{i l}-P_{i 0},
$$

where $\Delta P_{i l}$ is the average appreciation per square metre of the residential district $l$ within the impact scope of the station $i(l=1,2,3, \ldots, L$, and $L$ is the sample set size for the station $i) . P_{i l}$ is the average price per square metre of the residential district $l$ within the impact scope of the station $i$. $P_{i 0}$ is the average price per square metre of the residential district on the border of the impact scope. If the calculated result is positive, it means the impact of urban rail transit on residential property value is positive; otherwise, the impact is negative.

\section{STUDY AREA AND DATA}

The study area is the city of Shanghai, located in the Yangtze River Delta in East China. Shanghai is one of the global financial centres, with a population of more than 25 million as of 2014. As of the end of June 2014, 14 rail transit lines have been operated in Shanghai (excluding the maglev line). Shanghai Metro Line 11 crosses from the CBD to the

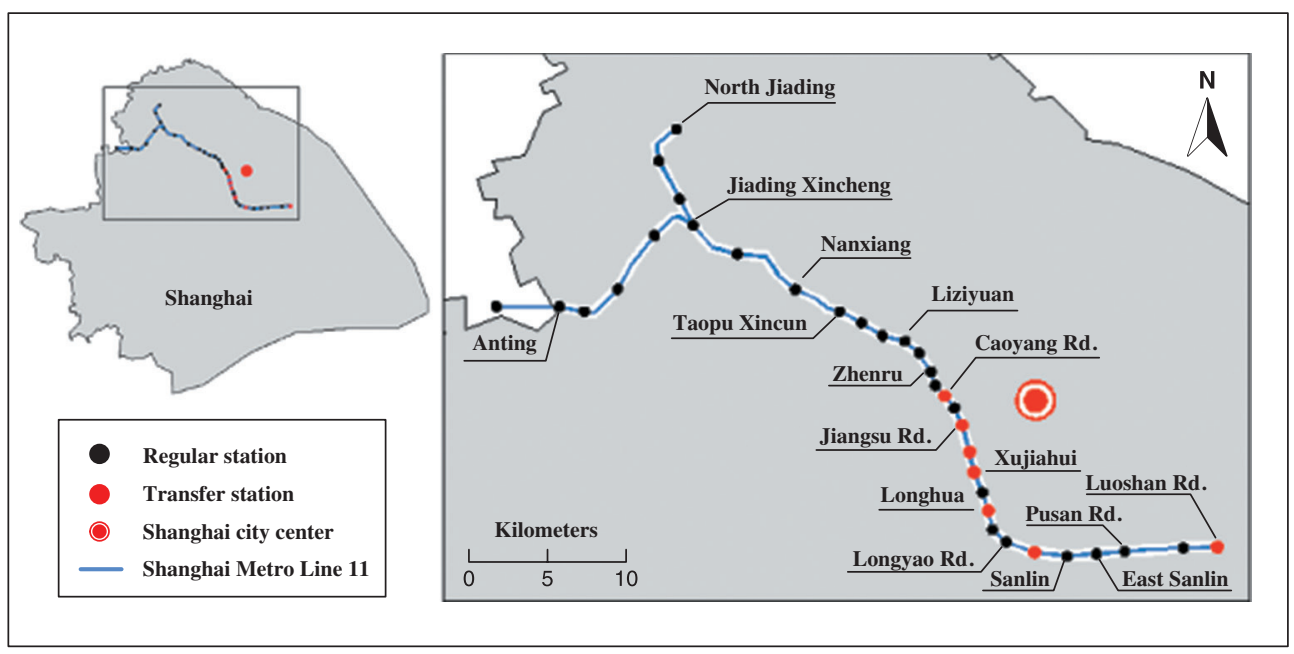

Figure 1: Shanghai Metro Line 11. 
north-western outskirts of Shanghai. To ensure that the impact scopes of adjacent stations do not overlap and the residential property price data within the impact scope is rich and evenly distributed, 16 newly built stations of Line 11 between 2009 and 2013 are taken into consideration as a case study (see Fig. 1).

Data for this study are gathered from various sources and all of them are from 2014 to maintain consistency. The accessibility improvement data include information of rail travel, bus travel, population and employment. Rail travel information comes from the Shanghai Metro official web site; bus travel information comes from the Shanghai GIS map with the city's bus transit network loaded; population and employment information come from Shanghai Statistical Yearbook and field survey. The residential price data come from various online real estate platforms and include information of average price per square metre and network distance to the nearest station for 2,236 residential districts which have similar main physical characteristics.

The parameters that cannot be obtained by actual survey will be referred to previous research literature and reports. The waiting time is set as half of the departure interval in the peak period; the time value is set as 20 yuan per hour referring to the income level per capita in Shanghai (Shanghai Statistical Yearbook, 2013); the daily travel frequency per capita is set as 2 referring to the report on the fourth comprehensive traffic survey in Shanghai (2010); the residential area per capita is set as $30 \mathrm{~m}^{2}$ referring to Statistical Bulletin of Urban Housing Overview (2003) and Shanghai Statistical Yearbook (2013); the penalty coefficient of the shuttle transportation time, waiting time and transfer time is set as 1.5 compared to the time on the subway or in the bus.

\section{RESULTS AND DISCUSSION}

By eqns (3-7), the travel accessibility improvement average per square metre $\overline{A_{i}}$, the attract accessibility improvement average per square metre $\overline{B_{i}}$ and the residential property average appreciation per square metre $\overline{\Delta P_{i}}$ within the impact scope of each station could be calculated. The results and analysis are shown in Table $1 . T_{i}$ is the travel time by urban rail transit from the station $i$ to the city centre station. $\overline{D_{i}}$ is the sum of $\overline{A_{i}}$ and $\overline{B_{i}} ; H_{i}$ is the ratio of $\overline{A_{i}}$ and $\overline{B_{i}}$.

It can be seen from Table 1 that both of the residential property average appreciations and the accessibility improvement average values show the trend that they are larger in the suburb but smaller in the city centre in Shanghai. The relationship between the travel accessibility improvement and the attract accessibility improvement will be discussed, as well as the relationship between the accessibility improvement and the residential property average appreciation.

\subsection{Relationship between travel accessibility improvement and attract accessibility} improvement

It can be seen from Table 1 that $H_{i}$ increases significantly with the increase of travel time to the city centre station (see Fig. 2). In the station areas away from the city centre (Anting, North Jiading, Jiading Xincheng, Nanxiang, Taopu Xincun, Sanlin, East Sanlin, Pusan Rd. and Luoshan Rd.), the ratio is 1.5-2, suggesting that the travel benefit is 1.5-2 times the agglomeration benefit. In the station areas close to the city centre (Liziyuan, Zhenru, Caoyang Rd., Jiangsu Rd., Xujiahui, Longhua and Longyao Rd.), the ratio is less than 1, suggesting that the travel benefit is less than the agglomeration benefit.

The quality of public transportation in the suburb is generally worse than that in the city centre in Chinese cities. After the construction of the urban rail line, the transportation around the suburban station is improved significantly. So the travel benefit is more than the agglomeration benefit 
Table 1: Results and analysis of the accessibility improvement and the residential property average appreciation.

\begin{tabular}{lcccccc}
\hline Station name & $T_{i}(\mathrm{~min})$ & $\begin{array}{c}\overline{A_{i}} \\
\left(\text { yuan }^{-2}\right)\end{array}$ & $\begin{array}{c}\overline{B_{i}} \\
\left(\text { yuan }^{-2}\right)\end{array}$ & $\begin{array}{c}\overline{\Delta P_{i}} \\
/\left(\text { yuan }^{-2}\right)\end{array}$ & $\begin{array}{c}\overline{D_{i}} \\
\left(\text { yuan m}^{-2}\right)\end{array}$ & $H_{i}$ \\
\hline Anting & 65 & 334.3 & 175.7 & 2417.9 & 510.0 & 1.902 \\
North Jiading & 60 & 336.9 & 172.2 & 2395.7 & 509.1 & 1.956 \\
Jiading & 50 & 368.0 & 189.8 & 2827.0 & 557.8 & 1.939 \\
Xincheng & & & & & & \\
Nanxiang & 41 & 233.9 & 124.6 & 2087.3 & 358.5 & 1.877 \\
Taopu Xincun & 37 & 182.8 & 101.2 & 1314.2 & 284.0 & 1.805 \\
Liziyuan & 29 & 153.4 & 172.0 & 1928.0 & 325.4 & 0.892 \\
Zhenru & 24 & 120.5 & 140.6 & 1369.6 & 261.1 & 0.857 \\
Caoyang Rd. & 19 & 141.2 & 224.5 & 1820.6 & 365.7 & 0.629 \\
Jiangsu Rd. & 8 & 56.2 & 91.9 & 1102.9 & 148.1 & 0.611 \\
Xujiahui & 12 & 91.7 & 147.1 & 1232.1 & 238.8 & 0.623 \\
Longhua & 24 & 128.3 & 147.6 & 1555.3 & 275.9 & 0.869 \\
Longyao Rd. & 26 & 207.7 & 223.4 & 2063.4 & 431.1 & 0.930 \\
Sanlin & 28 & 247.3 & 164.9 & 2286.3 & 412.2 & 1.5 \\
East Sanlin & 30 & 252.0 & 168.0 & 2092.3 & 420.0 & 1.5 \\
Pusan Rd. & 32 & 251.5 & 167.7 & 2188.4 & 419.2 & 1.5 \\
Luoshan Rd. & 40 & 414.1 & 276.1 & 3773.0 & 690.2 & 1.5 \\
\hline
\end{tabular}

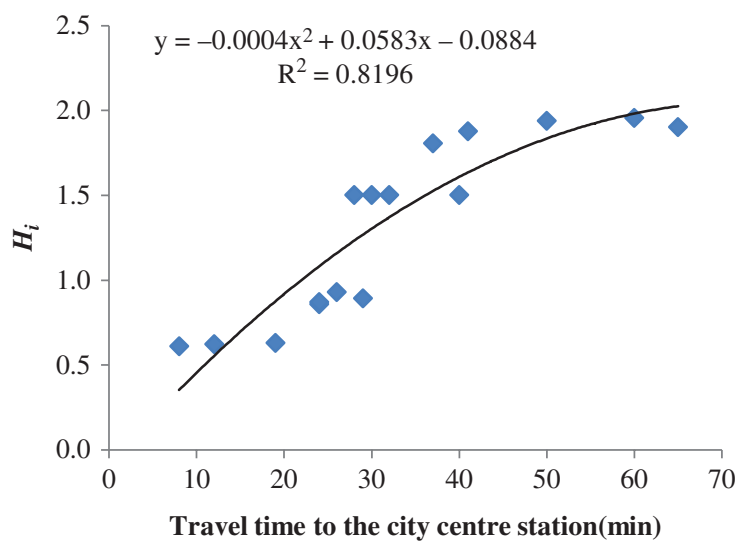

Figure 2: Relationship between $H_{i}$ and the travel time to the city centre station.

in the suburban station areas. On the other hand, the introduction of the urban rail line attracts more travellers over a long distance to the station areas close to the city centre on employment and consumption. So the agglomeration benefit is more than the travel benefit in the urban station areas. That is the reason why the relationship between the travel benefit and the agglomeration 
benefit in the suburban station area and in the urban station area is distinct. Further explanations to this phenomenon will be made by analysing representative stations as below.

\subsubsection{Luoshan Rd. station}

Luoshan Rd. station is in the suburban area of Shanghai, and the linear distance to the city centre is about $15 \mathrm{~km}$. Before the opening of the rail station, public transportation was very poor (see Fig. 3).

After the opening of Luoshan Rd. station, public transportation is improved significantly. There are 9 bus stops in the range of $500 \mathrm{~m}$ around Luoshan Rd. station, which is convenient for travellers to transfer from bus to subway (see Fig. 4).

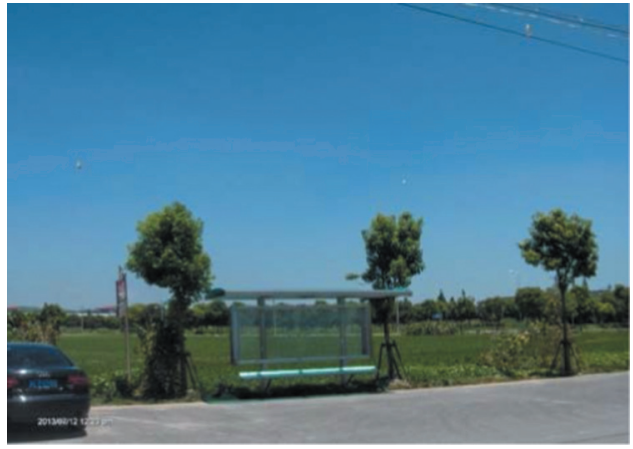

(a) Bus stop not in use around the station.

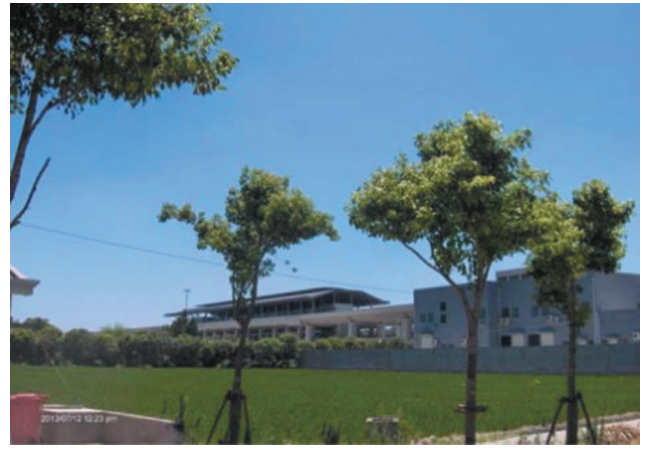

(b) Land use around the station.

Figure 3: Public transportation and land use before the opening of Luoshan Rd. station.

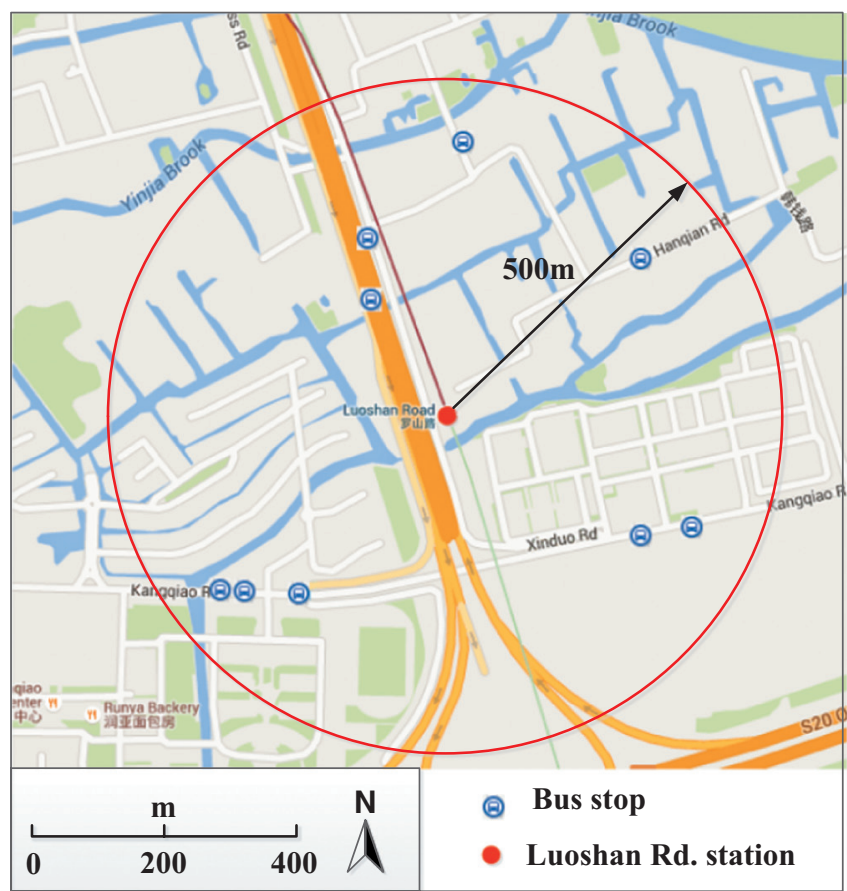

Figure 4: Bus stops in the range of $500 \mathrm{~m}$ around Luoshan Rd. rail station. 


\subsubsection{Xujiahui station}

Xujiahui station is a three-line transfer station of Line 1, Line 9 and Line 11, located in the Shanghai core area. Xujiahui is one of the four commercial circles in Shanghai. Agglomeration benefits are strengthened significantly due to the opening of rail lines, which can be seen in Fig. 5.

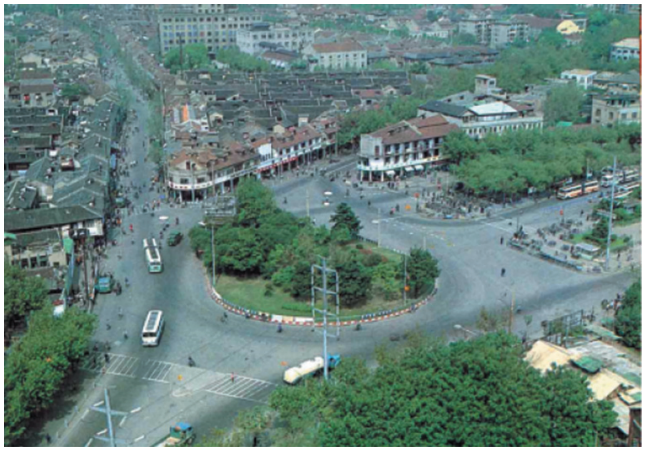

(a) Xujiahui core area in the 1980s.

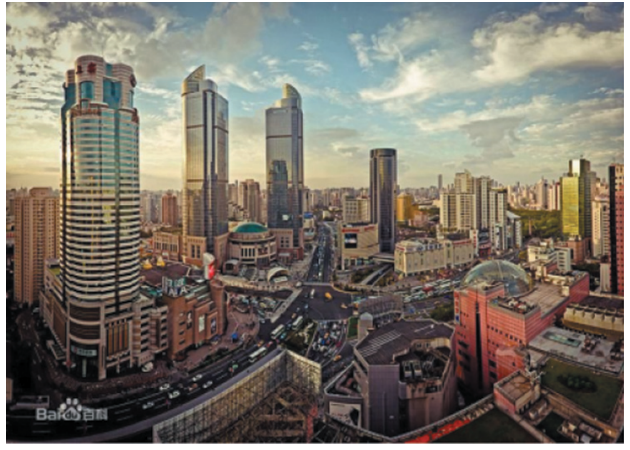

(b) Xujiahui core area in $21^{\text {st }}$ century.

Fiugre 5: Xujiahui core area development after the opening of rail lines [13].

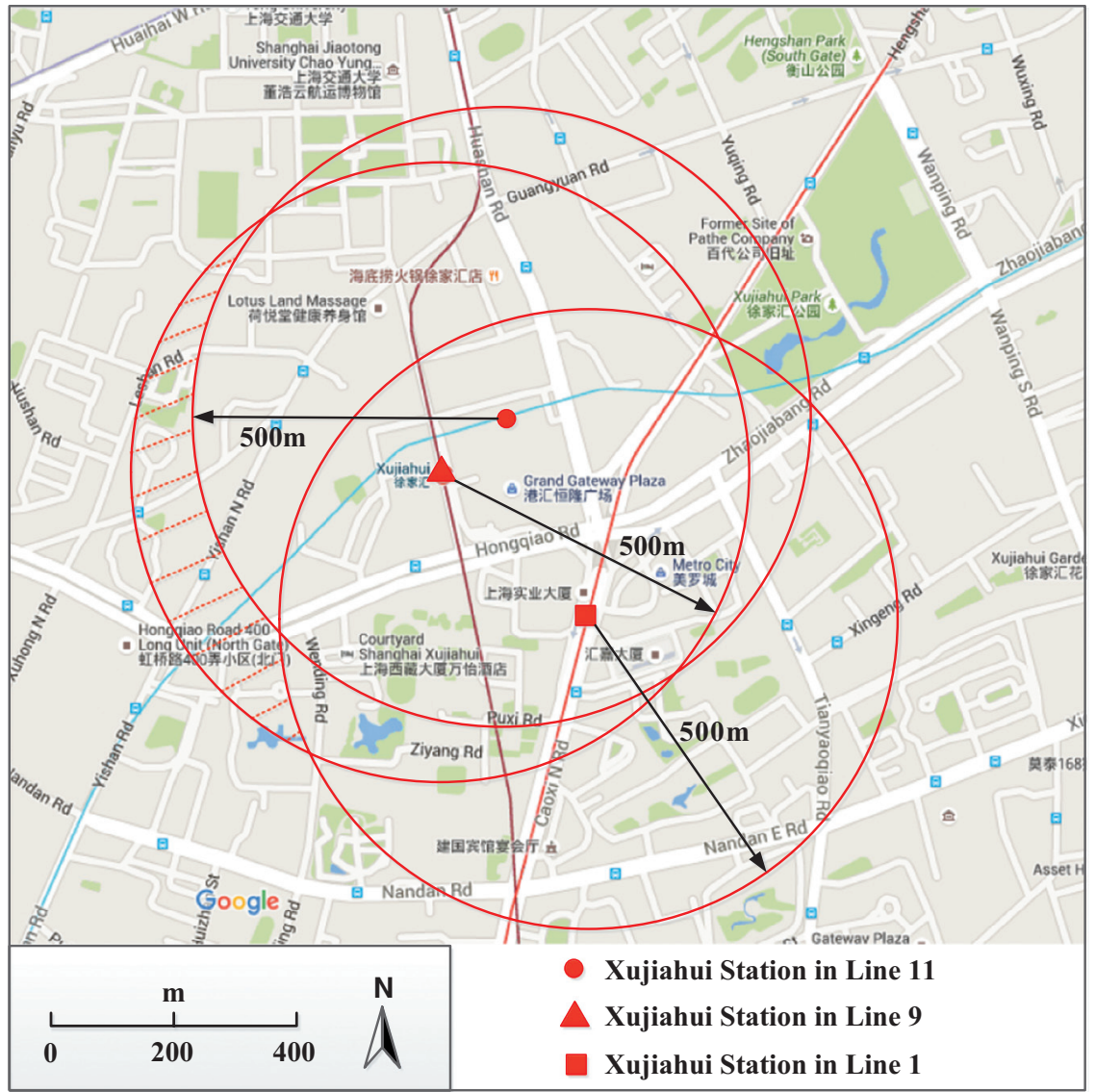

Figure 6: $500 \mathrm{~m}$ walking distance around Xujiahui station. 
Line 1 and Line 9 were opened in 1993 and 2007, respectively. Line 11 was opened in 2009 and brought convenience for travellers from Jiading district to the city core area. The opening of Line 11 also expanded the scope of the $500 \mathrm{~m}$ walking distance around Xujiahui station, as the shaded part shows in Fig. 6.

Through the analysis given earlier, the traffic benefit is greater than the agglomeration benefit in suburban area, which is completely different in the city centre. Therefore, the suburban station should be considered to strengthen the traffic function and improve the shuttle transportation while the urban station should be considered to connect with the surrounding commercial building and provide convenience for travellers when planning urban rail transit stations.

\subsection{Relationship between accessibility improvement and residential property appreciation}

The accessibility improvement average value is significantly associated with the residential property average appreciation (see Fig. 7).

The fitting function coefficient is 4.77 , close to 5 , suggesting that the residential property appreciation is about 5 times the accessibility improvement value per year. The goodness-offit of the model is greater than 0.93. In theory, the fitting line should be through the origin of coordinates. In fact, the intercept is 176.63 in this case study because of bias. But compared to the appreciations level, the intercept is close to zero.

\section{CONCLUSIONS}

The introduction of urban rail transit benefits to the accessibility and land development of the city. One of the most significant benefits is the impact on property values. A new approach which researches the impacts of urban rail transit on residential property values has been proposed here. The impacts of urban rail transit on residential property values have been classified into traffic effects and agglomeration effects, which are measured by the travel accessibility improvement and the attract accessibility improvement, respectively. A case on 16 stations of Shanghai Metro Line 11 has been studied to verify the accessibility improvement model, whose goodness-of-fit is greater than $93 \%$. Both of the residential property average appreciation and the accessibility improvement average value show the trend that they are

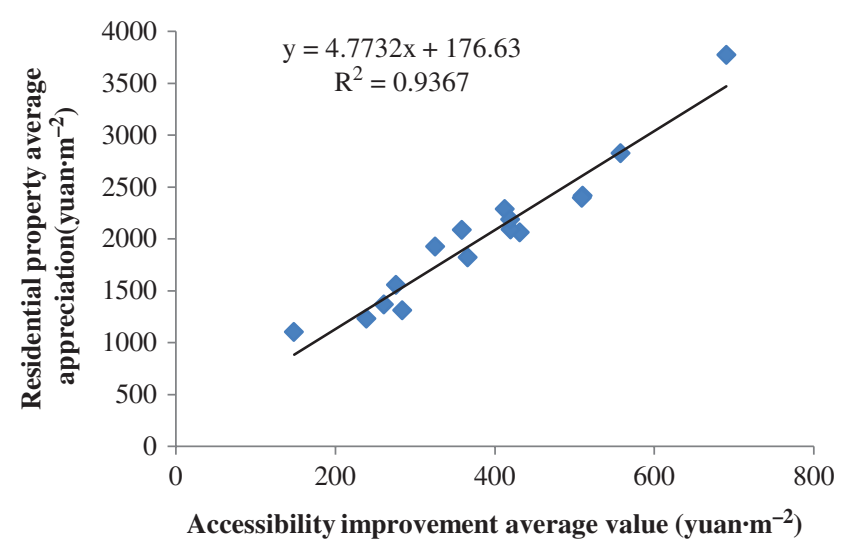

Figure 7: Relationship between the accessibility improvement average value and the residential property average appreciation per square metre. 
larger in the suburb but smaller in the city centre. Traffic benefit is greater than agglomeration benefit in the suburb, which is completely different in the city centre. Furthermore, the residential property appreciation is about 5 times the accessibility improvement value per year.

It should be noted that the research findings are subject to the specific selected data samples and only reflect the case of Shanghai Metro in the given period of examination. Future studies will consider a more detailed and generalized analysis of such phenomenon for other cities in developing countries like China, as property value impacts of urban rail transit consist of the basis for value capture, providing finance in the development of new rail lines.

\section{REFERENCES}

[1] Medda, F., Land value capture finance for transport accessibility: a review. Journal of Transport Geography, 25, pp. 154-161, 2012. DOI: 10.1016/j.jtrangeo.2012.07.013

[2] Cervero, R. \& Landis, J., Assessing the impacts of urban rail transit on local real estate markets. Transportation Research A, 27, pp. 13-22, 1993. DOI: 10.1016/09658564(93)90013-B.

[3] Du, H. \& Mulley, C., The short-term land value impacts of urban rail transit: quantitative evidence from Sunderland, UK. Land Use Policy, 24(1), pp. 223-233, 2007. DOI: 10.1016/j.landusepol.2005.12.003.

[4] Pagliara, F. \& Papa, E., Urban rail systems investments: an analysis of the impacts on property values and residents' location. Journal of Transport Geography, 19(2), pp. 200-211, 2011. DOI: 10.1016/j.jtrangeo.2010.02.006.

[5] Lancaster, K.J., A new approach to consumer theory. Journal of Political Economy, 74(2), pp. 132-157, 1966. DOI: 10.1086/259131.

[6] Rosen, S., Hedonic prices and implicit markets: product differentiation in pure competition. Journal of Political Economy, 82(1), pp. 34-55, 1974. DOI: 10.1086/260169.

[7] Bowes, D.R. \& Keith, R.I., Identifying the Impacts of Rail Transit Stations on Residential Property Values. Journal of Urban Economics, 50(1), pp. 1-25, 2001. DOI: 10.1006/juec.2001.2214.

[8] Seo, K., Golub, A. \& Kuby, M., Combined impacts of highways and light rail transit on residential property values: a spatial hedonic price model for Phoenix, Arizona. Journal of Transport Geography, 41(0), pp. 53-62, 2014. DOI: 10.1016/j.jtrangeo.2014.08.003.

[9] Wu, Q., Ye, X. \& Lin, X., Attraction area model for urban rail transit stations. Journal of Tongji University (Natural Science), 42(7), pp. 1058-1063, 2014.

[10] Wu, Q. \& Ye, X., Analysis of relationships between urban rail transit accessibility improvement and residential property appreciations. Journal of Tongji University (Natural Science), 44(6), pp. 899-906, 2016.

[11] Dube, J., Theriault, M. \& Des, R.F., Commuter rail accessibility and house values: The case of the Montreal South Shore, Canada, 1992-2009. Transportation Research Part A-Policy and Practice, 54, pp. 49-66, 2013.

[12] Kay, A.I., Noland, R.B. \& DiPetrillo, S., Residential property valuations near transit stations with transit-oriented development. Journal of Transport Geography, 39, pp. 131-140, 2014. DOI: 10.1016/j.jtrangeo.2014.06.017.

[13] Image, www.baidu.com. Accessed: May 26, 2016. 